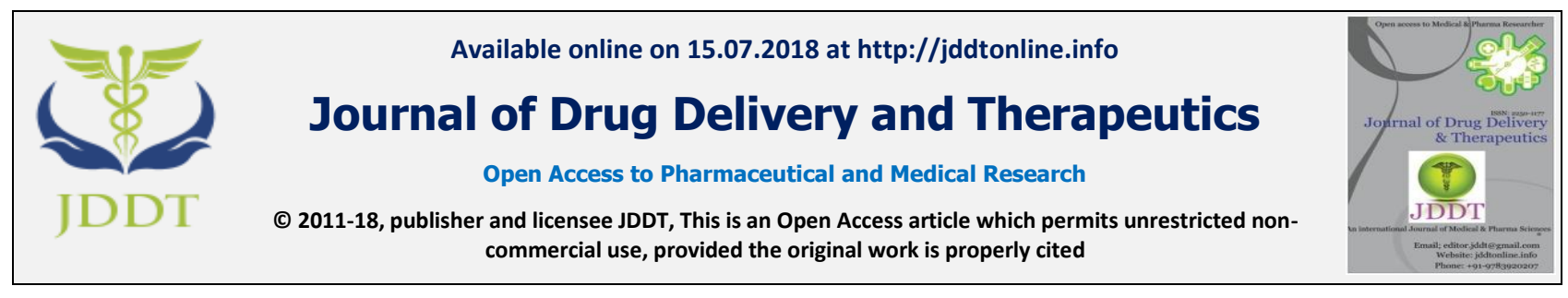

Open 6 Access

Review Article

\title{
NIPAH VIRUS INFECTION: A GROWING DEADLY PARAMYXOVIRUS AND THE RECENT STATUS OF POTENTIAL THERAPEUTICS IN INDIA
}

\author{
Singh Asheesh*1, Singh Parul ${ }^{2}$ \\ ${ }^{1}$ VNS Faculty of pharmacy, Vidya Vihar, Neelbud, Nathu Berkheda, Bhopal, M.P., India-462044 \\ ${ }^{2}$ Department of pharmacy, Guru Ghasidas University, Bilaspur (India)-495009
}

\section{ABSTRACT}

Nipah virus is an RNA virus that is part of the Paramyxovidae family that was first identified as a zoonotic pathogen after an outbreak involving severe respiratory illness in pigs and encephalitic disease in humans in Malaysia and Singapore in 1998 and 1999. Nipah virus can cause a range of mild to severe disease in domestic animals such as pigs. Nipah virus infection in humans causes a range of clinical presentations, from asymptomatic infection (subclinical) to acute respiratory infection and fatal encephalitis. Nipah virus can be transmitted to humans from animals (bats, pigs), and can also be transmitted directly from humanto-human. Fruit bats of the Pteropodidae family are the natural host of Nipah virus. There is no treatment or vaccine available for either people or animals. A recombinant measles virus (rMV) vaccine expressing NiV envelope glycoproteins is proposed but is still under trial. The primary treatment for humans is supportive care. Nipah virus is an emerging threat to the human life with history of outbreaks chiefly in Bangladesh, India \& Malaysia. Categorized as zoonotic biosafety level 4 (BSL4) agent depending upon the geographic locations of outbreaks, it is responsible of case mortality between $40 \%$ to $100 \%$ in both humans and animals thus one of the most deadly virus known to infect humans. The present review article cover current potential therapeutics in India against nipah virus infection.

Keywords: Nipah, Virus, Infection, Hendra virus, paramyxoviruses, Human being

Article Info: Received 05 March, 2018; Review Completed 29 May 2018; Accepted 01 June 2018; Available online 15 July 2018

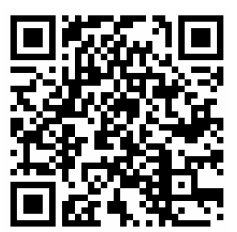

\section{Cite this article as:}

Singh A, Singh P, Nipah virus infection: a growing deadly paramyxovirus and the recent status of potential therapeutics in India, Journal of Drug Delivery and Therapeutics. 2018; 8(4):36-41 DOI: http://dx.doi.org/10.22270/jddt.v8i4.1739

*Address for Correspondence:

Asheesh Singh, Senior Research Scientist, VNS Faculty of pharmacy, Vidya Vihar, Neelbud, Nathu Berkheda, Bhopal, Madhya Pradesh, India 462044

\section{INTRODUCTION}

Nipah virus was first recognized in 1999 during an outbreak among pig farmers in Kampung Sungai Nipah, Malaysia. No new outbreaks have been reported in Malaysia and Singapore since 1999. NiV (Nipah virus) was first recognized in Bangladesh in 2001 and nearly annual outbreaks have occurred in that country since, with disease also identified periodically in eastern India $^{1-}$ 2. Other regions may be at risk for $\mathrm{NiV}$ infection, as serologic evidence for $\mathrm{NiV}$ has been found in the known natural reservoir (Pteropus bat species) and several other bat species in a number of countries, including Cambodia, Thailand, Indonesia, Madagascar, Ghana and the Philippines. Nipah virus $(\mathrm{NiV})$ is an emerging zoonotic virus (a virus transmitted to humans from animals $)^{3-4}$. In infected people, Nipah virus causes a range of illnesses from asymptomatic (subclinical) infection to acute respiratory illness and fatal encephalitis. NiV can also cause severe disease in animals such as pigs, resulting in significant economic losses for farmers. Although Nipah virus has caused only a few outbreaks, it infects a wide range of animals and causes severe disease and death in people, making it a public health concern. More than $60 \%$ of the newly identified infectious agents that have affected people 
over the past few decades have been caused by pathogens originating from animals or animal products. Of these zoonotic infections, $70 \%$ originate from wildlife. Bats have been recognized to be important reservoir of zoonotic viruses, including Ebola, Marburg, SARS and Melaka viruses ${ }^{5}$. In this context, Nipah Virus (NiV) represents another new emerging zoonosis, one of the most important bat-borne pathogens discovered in recent history. In 1998 a dangerous new virus emerged in Malaysia ${ }^{6}$. Initially thought to be a form of Japanese Encephalitis, it was later identified as a new zoonotic disease and named Nipah after the village of "Sungai Nipah" where it was first identified. Similarly, at the beginning in pigs it was confused with Classical swine fever. In infected people, Nipah virus causes severe and commonly lethal illness. It can also cause severe disease in animals such as pigs, and may require the application of stamping out policy, thus resulting in significant economic losses for farmers ${ }^{7}$. The National Centre for Disease Control has issued high alert across the country after an outbreak of the Nipah virus (NiV) infection in Kerala.

Since their initial recognition, Nipah and Hendra viruses have repeatedly re-emerged. In total, $13 \mathrm{HeV}$ (Hendra virus) outbreaks have occurred in Australia in 1994, 1999, 2004, and 2006-2009, and have always involved horses as an intermediate host with some human infections including four fatalities, the most recent in September $2009^{8-10}$. NiV has also repeatedly caused spill-over events involving hundreds of human cases since 1998 with at least nine recognized occurrences primarily in Bangladesh and India since 2001 with the most recent in March $2008^{11}$. Several of the more recent $\mathrm{NiV}$ outbreaks have had higher rates of acute respiratory distress syndrome in conjunction with encephalitis, epidemiological findings consistent with multiple rounds of person-to-person transmission, higher case fatality rates $(\sim 75 \%)$, and direct transmission of virus from flying foxes to humans via contaminated food has been demonstrated $^{12-13}$. In addition to their highly pathogenic nature, the henipaviruses are also distinguished from all other paramyxoviruses by their unusually broad host tropism. Host cell infection by $\mathrm{NiV}$ and $\mathrm{HeV}$ requires two membrane-anchored envelope glycoproteins; the attachment (G) glycoprotein which binds the viral receptor, and the fusion $(\mathrm{F})$ glycoprotein which drives virus-host cell membrane merger ${ }^{14}$. The henipavirus $G$ glycoprotein lacks hemagglutinin and neuraminidase activities and the $\mathrm{F}$ glycoprotein is a typical class I fusion glycoprotein ${ }^{15-16}$. The host cell membrane anchored proteins, ephrin-B2 and ephrin-B3 ligands, have been shown to be the receptors employed by the henipaviruses ${ }^{17-22}$. There are presently no licensed therapeutics available to treat infection caused by the henipaviruses. Recently, some scientist isolated and extensively characterized a neutralizing human monoclonal antibody (hmAb), m102.4, which recognizes the receptor binding domain of the $\mathrm{HeV}$ and NiV G glycoproteins. This human monoclonal antibody potently neutralized both viruses in vitro and maintained its biological activity in vivo suggesting its possible utility as a passive therapeutic modality following henipavirus infection ${ }^{23}$.

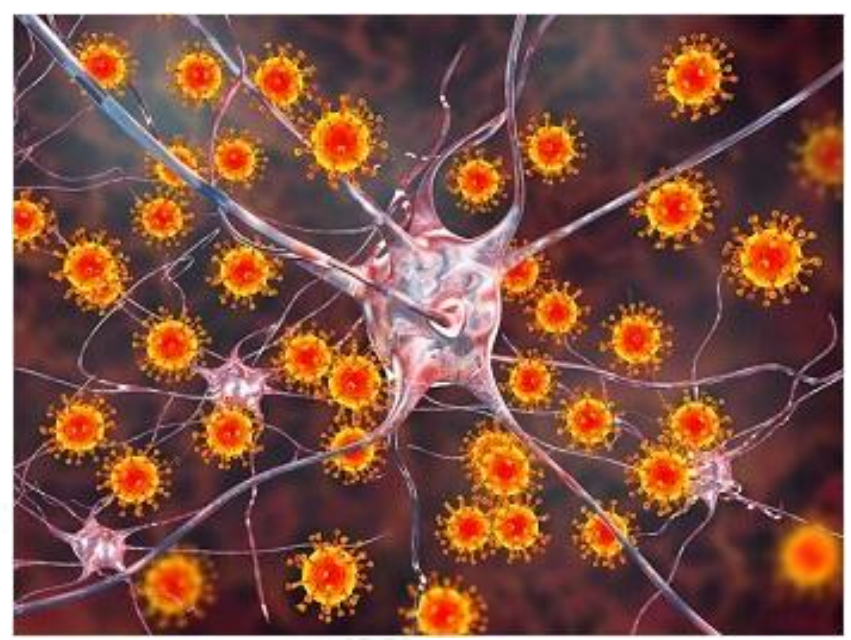

Figure 1: Nipah falls under the category of Zoonotic diseases like Ebola, HIV, mad cow disease and rabies, which can spread from animals to humans.

\section{EPIDEMIOLOGY}

Intensive agriculture has been implicated in the transmission of the deadly Nipah virus to humans. Between the 1970s and the 1990s, pig and mango production tripled in Malaysia. Mango trees were typically planted near pig enclosures, attracting fruit bats to the area. As bats fed and roosted in the trees, nearby livestock became infected with Nipah virus, which eventually spread to farm labourers. It is assumed that the geographic distribution of Henipaviruses overlaps with that of Pteropus category. This hypothesis was reinforced with the evidence of Henipavirus infection in Pteropus bats from Australia, Bangladesh, Cambodia, China, India, Indonesia, Madagascar, Malaysia, Papua New Guinea, Thailand and Timor-Leste ${ }^{24}$. Furthermore, the detection of antibodies against Nipah and Hendra viruses in straw-colored fruit bat (Eidolon helvum), indicates that these viruses might be present within the geographic distribution of Pteropodidae bats, not only in Asia, but extended to Africa, Arabian Peninsula coast, Middle-East, Cyprus and Southern Turkey ${ }^{25-26}$.

Table 1: Henipavirus Outbreaks and Pteropus Distribution Map

\begin{tabular}{|c|l|}
\hline $\begin{array}{c}\text { Countries with reported outbreak of at risk based on } \\
\text { serological evidence or molecular detection in Pteropus bats }\end{array}$ & $\begin{array}{l}\text { Australia, Bangladesh, Cambodia, China, India, } \\
\text { Indonesia, Madagascar, PNG Taiwan, Thailand }\end{array}$ \\
\hline Home range of Pteropus bats & $\begin{array}{l}\text { Bhutan, Brunei, China, India, Indonesia, Laos, } \\
\text { Madagascar, Myanmar, Nepal, Philippines, PNG, } \\
\text { Singapore, Taiwan, Thailand, Vietnam }\end{array}$ \\
\hline
\end{tabular}




\section{TRANSMISSION}

$\mathrm{NiV}$ is a zoonotic virus (a virus transmitted to humans from animals). During the initial outbreaks in Malaysia and Singapore, most human infections resulted from direct contact with sick pigs or their contaminated tissues. Transmission is thought to have occurred via respiratory droplets, contact with throat or nasal secretions from the pigs, or contact with the tissue of a sick animal. In the Bangladesh and India outbreaks, consumption of fruits or fruit products (e.g. raw date palm juice) contaminated with urine or saliva from infected fruit bats was the most likely source of infection. Limited human to human transmission of $\mathrm{NiV}$ has also been reported among family and care givers of infected NiV patients. During the later outbreaks in Bangladesh and India, Nipah virus spread directly from human-to-human through close contact with people's secretions and excretions. In Siliguri, India, transmission of the virus was also reported within a health-care setting (nosocomial), where $75 \%$ of cases occurred among hospital staff or visitors. From 2001 to 2008, around half of reported cases in Bangladesh were due to human-to-human transmission through providing care to infected patients ${ }^{27-28}$

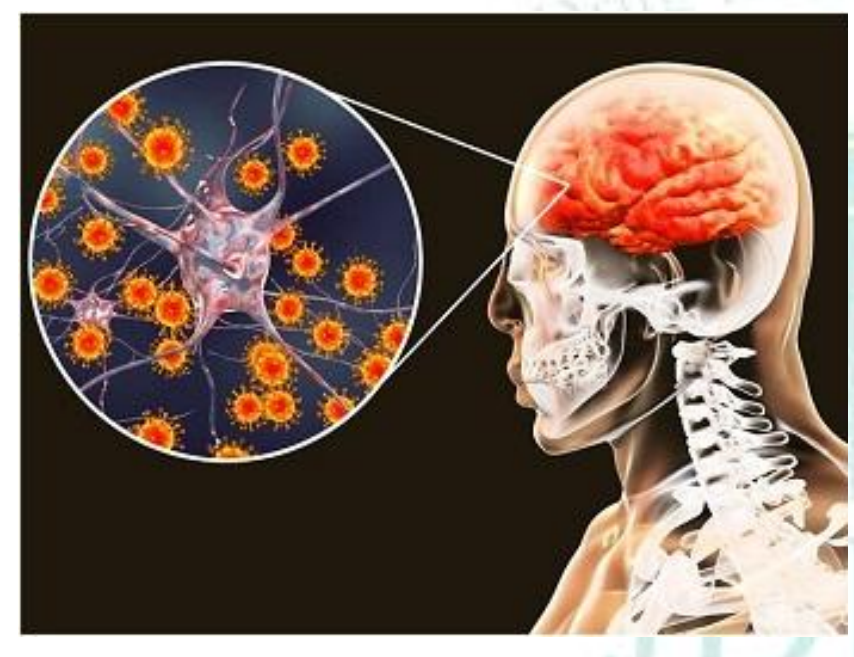

Figure 2: Nipah is fatal in a large number of cases and has a fatality rate between $40-75 \%$ according to the WHO. According to a research conducted in Bangladesh, it had a fatality rate of $54 \%$, i.e. 315 deaths occurred out of the 582 cases studied.

\section{SIGNS AND SYMPTOMS}

In Human: Infection with Nipah virus is associated with encephalitis (inflammation of the brain). After exposure and an incubation period of 5 to 14 days, illness presents with 3-14 days of fever and headache, followed by drowsiness, disorientation and mental confusion. These signs and symptoms can progress to coma within 24-48 hours. Some patients have a respiratory illness during the early part of their infections, and half of the patients showing severe neurological signs showed also pulmonary signs. During the Nipah virus disease outbreak in 1998-99, 265 patients were infected with the virus. About $40 \%$ of those patients who entered hospitals with serious nervous disease died from the illness. Long-term sequelae following Nipah virus infection have been noted, including persistent convulsions and personality changes. Latent infections with subsequent reactivation of Nipah virus and death have also been reported months and even years after exposure ${ }^{29-30}$.

In domestic animals: Nipah outbreaks in pigs and other domestic animals (horses, goats, sheep, cats and dogs) were first reported during the initial Malaysian outbreak in 1999. Many pigs had no symptoms, but others developed acute febrile illness, laboured breathing, and neurological symptoms such as trembling, twitching and muscle spasms.

Other species: Limited clinical information exists for other species. In dogs, distemper-like syndrome was described with pyrexia, depression, dyspnoea and conjunctivitis with purulent ocular-nasal discharge. Severe disease with mortality was also reported. NiV infection was confirmed by immuno histochemical examination of 1 dead and 1 dying dog from the epidemic area in Malaysia. Both showed histologic evidence of severe disease. Morbidity in dogs during outbreaks in Malaysia was interestingly high, with a seroprevalence from $15 \%$ up to $46 \%$. Nipah affected cats were observed on farms during outbreaks in Malaysia and some of these resulted in death. Experimental intranasal and oral inoculation of cats produced clinical disease characterized by acute febrile course with respiratory complications. Fruit bats show no serious signs of infection.

Diagnosis: Laboratory diagnosis of a patient with a clinical history of NiV can be made during the acute and convalescent phases of the disease by using a combination of tests. Virus isolation attempts and real time polymerase chain reaction (RT-PCR) from throat and nasal swabs, cerebrospinal fluid, urine, and blood should be performed in the early stages of disease. Antibody detection by ELISA (IgG and IgM) can be used later on. In fatal cases, immunohistochemistry on tissues collected during autopsy may be the only way to confirm a diagnosis.

\section{CONTROLLING NIPAH VIRUS IN DOMESTIC WILDLIFE}

Currently, there are no vaccines available against Nipah virus. Routine and thorough cleaning and disinfection of pig farms (with appropriate detergents) may be effective in preventing infection. If an outbreak is suspected, the animal premises should be quarantined immediately. Culling of infected animals - with close supervision of burial or incineration of carcasses - may be necessary to reduce the risk of transmission to people. Restricting or banning the movement of animals from infected farms to other areas can reduce the spread of the disease. As Nipah virus outbreaks in domestic animals have preceded human cases, establishing an animal health surveillance system, using a One Health approach, to detect new cases is essential in providing early warning for veterinary and human public health authorities ${ }^{31}$.

\section{Reducing the risk of contagion in Human Being}

In the absence of a licensed vaccine, the only way to reduce infection in people is by raising awareness of the risk factors and educating people about the measures they can take to reduce exposure to and decrease 
infection from NiV. Public health educational messages should focus on the following:

- Reducing the risk of bat-to-human transmission: Efforts to prevent transmission should first focus on decreasing bat access to date palm sap and to other fresh food products. Keeping bats away from sap collection sites with protective coverings (e.g., bamboo sap skirts) may be helpful. Freshly collected date palm juice should be boiled and fruits should be thoroughly washed and peeled before consumption.

- Reducing the risk of animal-to-human transmission: Gloves and other protective clothing should be worn while handling sick animals or their tissues, and during slaughtering and culling procedures. As much as possible, people should avoid being in contact with infected pigs.

- Reducing the risk of human-to-human transmission: Close unprotected physical contact with Nipah virus-infected people should be avoided. Regular hand washing should be carried out after caring for or visiting sick people.

Controlling infection in health-care settings: Healthcare workers caring for patients with suspected or confirmed $\mathrm{NiV}$ infection, or handling specimens from them, should implement standard infection control precautions for all patients at all times. As human-tohuman transmission in particular nosocomial transmission have been reported, contact and droplet precautions should be used in addition to standard precautions. Samples taken from people and animals with suspected $\mathrm{NiV}$ infection should be handled by trained staff working in suitably equipped laboratories ${ }^{32-}$ 33

\section{RECENT STATUS OF POTENTIAL THERAPEUTICS AND VACCINE DEVELOPMENT}

The recent emergence of these viruses and the sporadic nature of disease outbreaks have made the development and testing of vaccines and therapeutics for henipavirus infections a low commercial priority. However, the development of such countermeasures is a crucial component of any preparedness plan against an outbreak or emergence whether deliberate or natural. Vaccines have been used very successfully to control other wellknown and debilitating paramyxovirus infections including measles and mumps infection of humans and rinderpest virus infection of cattle. Vaccination with an attenuated live measles virus vaccine began in 1963 and was highly successful in reducing the infection rate with measles virus. In the United States alone, the first 20 years of vaccination is estimated to have prevented 52 million cases of the disease, 17,400 cases of mental retardation and 5200 deaths $^{34}$. As a result of vaccination the United States has been declared free of endemic measles ${ }^{35}$. Importantly, an historic announcement in May 2011 declared rinderpest as the first animal disease ever to be eradicated by humankind ${ }^{36}$. Vaccination was a central plank of the campaign to eradicate the virus. Successful resistance to paramyxovirus infection that is conferred by vaccination is commonly mediated by an adaptive immune response to viral surface proteins/glycoproteins particularly for infections associated with a viraemic phase such as those caused by the measles virus and the mumps virus ${ }^{37-39}$. Consequently, vaccine development for the henipaviruses has focused on the viral $F$ and $G$ envelope glycoproteins either expressed in a recombinant virus or as a recombinant subunit immunogen. Hamsters vaccinated with recombinant vaccinia viruses encoding $\mathrm{NiV} \mathrm{G}$ or $\mathrm{F}$ were protected against a lethal challenge with $\mathrm{NiV}$. However a strong anamnestic response to the challenge virus suggested that vaccination did not prevent virus replication ${ }^{40}$. Similarly, pigs vaccinated with canarypox viruses encoding either NIV G or F were protected against a lethal $\mathrm{NiV}$ infection and although virus was not reisolated from any tissues low levels of viral RNA were detected in several samples ${ }^{41}$.

The NiV envelope proteins $\mathrm{F}$ (fusion) and $\mathrm{G}$ (glycoprotein) were chosen for vaccine development, based on work by Guillaume et $\mathrm{al}^{42}$. with a vaccinia virus-based recombinant vaccine expressing the $\mathrm{NiV} \mathrm{F}$ and $\mathrm{G}$ proteins in golden hamsters and on knowledge of immunity to other paramyxoviruses. For example, antibodies against the measles virus $F$ protein contribute to virus neutralization, likely by preventing fusion of the virus with the cell membrane at the time of virus entry ${ }^{43}$. Antibodies against measles virus hemagglutinin $(\mathrm{H})$, the attachment protein of the virus analogous to the Nipah virus $G$ protein, are the most important neutralizing antibodies ${ }^{44-45}$. In addition, the $F$ and $G$ proteins may be involved in inducing the $\mathrm{CD} 8^{+}$cytotoxic $\mathrm{T}$-cell response to $\mathrm{NiV}$, analogous to the role of measles virus proteins $\mathrm{H}$ and $\mathrm{F}^{46}$. A previously developed NiV early-infection model in pigs was used in the challenge part of the work. The purpose of this study was to obtain preliminary data on the efficacy of a veterinary vaccine against $\mathrm{NiV}$ in target species by using for the first time in pigs the canarypox virus vector, which is proven and approved for commercial use in domestic animals. The aim of the vaccine was not only to prevent disease in animals but most importantly to prevent virus shedding, in order to protect the human population by breaking the chain of transmission and to stop virus spread in swine herds, especially in areas of endemicity. On the other hand, in areas where the virus is not endemic, where it may be introduced intentionally or by accident, the vaccination may be used in outbreak control, with emphasis on the rapid establishment of protective immunity in swine herds following vaccination. To meet the specific requirements, different optimal vaccination doses/regimens may need to be designed ${ }^{47}$. Several studies have also been carried out with a $\mathrm{HeV}$ recombinant soluble $\mathrm{G}$ glycoprotein (sG)-based subunit immunogen $(\mathrm{HeVsG})$. In one experimental study, cats survived a lethal NiV challenge with no clinical signs and the data supported the development of sterilizing immunity in this animal model. In a second study carried out in cats, virus was reisolated from one vaccinated animal and viral RNA was detected in the brains of several animals receiving the two highest doses of vaccine $e^{48-49}$. The authors speculated that the detection of genome in the brain in the face of significant levels of neutralizing antibody prior to challenge indicated that 'a persistent infection might 
occur despite pre-existing immunity'. In a vaccine antigen dose sparing study, ferrets immunized with $\mathrm{HeVsG}$ survived an otherwise lethal $\mathrm{HeV}$ challenge. Here, all vaccine antigen doses prevented clinical disease and there was no anamnestic antibody response detected following challenge, nor could any challenge virus be reisolated from any animal ${ }^{50}$. While all three of these studies utilized $\mathrm{HeVsG}$ as the vaccine immunogen, variations in adjuvant used, immunogen dose and challenge virus dose make it difficult to directly compare the experimental outcomes. However, the results of two of three studies indicate that it is possible to prevent establishment of a $\mathrm{HeV}$ infection by vaccination, and indeed all three studies indicated that vaccination could prevent clinical illness.

Development of an effective vaccine ideally requires an understanding of how the agent in question interacts with the host to cause disease. Anterograde infection of the brain has been proposed in henipavirus infection, as well as infection via the systemic route. In addition to preventing systemic disease, an ideal vaccine would prevent infection of the CNS by either route and thus eliminate the possibility of recrudescent CNS disease vaccination against measles virus did reduce the incidence of persistent infection manifested as SSPE. Clinical trials of a potential vaccine against a BSL-4 agent could not be carried out in humans; instead there is a requirement by the U.S. FDA that candidate vaccines be tested in at least two different animal models ${ }^{51}$. Relevant animal models that reproduce the nervous and systemic aspects of henipavirus infection and a thorough understanding of henipavirus pathogenesis in these animal models will be essential to this activity. To this end, the development of a model for henipavirus infection in a non-human primate (African green monkey) was an important step, and indeed disease progression mediated by either $\mathrm{HeV}$ or $\mathrm{NiV}$ in these animals essentially mirrors that seen in humans. Other species that may be suitable include golden hamsters, ferrets and cats ${ }^{52}$.

The strategy for the deployment of successful therapeutics is relatively straightforward but a successful vaccine may be deployed differently in different circumstances. While the outbreaks caused by henipa viruses remain sporadic in nature and involve

\section{REFERENCES}

1. Lu G, Liu D. SARS-like virus in the Middle East: a truly batrelated coronavirus causing human diseases. Protein Cell 2012; 3:803-805.

2. Field H, Young P, Yob JM, Mills J, et al. The natural history of Hendra and Nipah viruses. Microbes Infect 2001; 3:307314.

3. Leroy EM, Kumulungui B, Pourrut X, Rouquet P, Hassanin A. Fruit bats as reservoirs of Ebola virus. Nature 2005; 438: 575 576.

4. Towner JS, Pourrut X, Albarino CG, et al. Marburg virus infection detected in a common African bat. PLoS One. 2007; 2:e764.

5. Li W, Shi Z, Yu M, et al. Bats are natural reservoirs of SARSlike coronaviruses. Science 2005; 310:676-679.

6. Chua K, Crameri G, Hyatt A, et al. A previously unknown reovirus of bat origin is associated with an acute respiratory relatively small numbers of people and animals (except in the NiV outbreak in Malaysia where over one million pigs were culled), mass vaccination is unlikely to be a viable approach. Vaccination of select human populations at risk may be warranted in some circumstances; one such population might be, for example, horse veterinarians and horse owners in north eastern Australia. However, the primary strategy for containing $\mathrm{HeV}$ outbreaks in Australia is to vaccinate horses in at-risk areas. Human infection with $\mathrm{HeV}$ is so far only known to have occurred via close contact with infected horses and so vaccination of horses would hopefully prevent the chain of transmission to humans. The same principle may apply if for instance, pigs (or any other animal) became a significant source of human infection, as seen in the initial NiV outbreak in Malaysia and Singapore. Should the nature of henipavirus outbreaks change or bioterrorism involving these agents become a reality then mass vaccination may become a viable option ${ }^{53-54}$.

\section{CONCLUSION}

Recent vaccine studies have demonstrated that henipavirus G-specific antibodies are critical for protection from disease. Evidence of passive protection against $\mathrm{NiV}$, and more recently $\mathrm{HeV}$, challenge using hamster polyclonal antiserum or murine (monoclonal antibodies) $\mathrm{mAbs}$ reactive to $\mathrm{NiV}$ glycoproteins was provided in the hamster. However, in those prior studies, both the challenge virus and antibodies were administered by intraperitoneal injection either simultaneously or immediately before or following challenge. Here we examined a neutralizing fully-human $\mathrm{mAb}$, with the potential for human use, in a consistently susceptible animal model where challenge and drug delivery mimicked a potential real-life scenario. Case management should be strengthened in all possible areas with proper preventive measures from viral hosts. More Studies should be done to assess the vaccines proposed and further research on treatment is necessitated.

\section{ACKNOWLEDGEMENTS}

Authors are thankful to VNS Institute of Pharmacy, Bhopal and Department of Pharmacy, GGU Bilaspur for providing the necessary facilities \& guidance to complete this review.

disease in humans. Proc Natl Acad Sci USA 2007; 104:1142411429.

7. Chua KB. Nipah virus outbreak in Malaysia. J Clin Virol 2003; 26:265-275.

8. Bishop K, Broder C. Hendra and Nipah: Lethal Zoonotic Paramyxoviruses. In: Scheld WM, Hammer SM, Hughes JM, editors. Emerging Infections. Washington, D.C.: American Society for Microbiology. 2008; 155-187.

9. Li Y, Wang J, Hickey AC, et al. Antibodies to Nipah or Nipah-like viruses in bats, China. Emerg Infect Dis 2008; 14:1974-1976.

10. Hayman T, Suu-Ire R, Breed A, et al. Evidence of henipavirus infection in West African fruit bats. PLoS ONE 2008; 3:2739.

11. Anonymous. Hendra Virus, Human, Equine - Australia (07): (Queensland). Pro-MED International Society for Infectious Diseases. 2008; 20080821-2606. 
12. Anonymous. Hendra Virus, Human, Equine - Australia (05): (Queensland) Pro-MED International Society for Infectious Diseases. 2009; 20090910-3189.

13. Anonymous. Nipah virus, fatal - Bangladesh (03). Pro-MED International Society for Infectious Diseases. 2008; 200803110979.

14. Gurley E, Montgomery J, Hossain M, et al. Person-to-person transmission of Nipah virus in a Bangladeshi community. Emerg Infect Dis 2007; 13:1031-1037.

15. Luby S, Rahman M, Hossain M, et al. Foodborne transmission of Nipah virus, Bangladesh. Emerg Infect Dis 2006 12: 1888-1894.

16. Harit AK, Ichhpujani RL, Gupta S, et al. Nipah/Hendra virus outbreak in Siliguri, West Bengal, India in 2001. Indian J Med Res 2006; 123:553-560.

17. Lamb R, Parks G. (2007) Paramyxoviridae: The viruses and their replication. In: Knipe DM, Howley PM, editors. Fields Virology. Lippincott Williams \& Wilkins.2007; 5:1449-1496.

18. Bossart K, Broder C. Paramyxovirus Entry. Adv Exp Med Biol. 2013; 790:95-127.

19. Bonaparte M, Dimitrov A, Bossart K, et al. Ephrin-B2 ligand is a functional receptor for Hendra virus and Nipah virus. Proc Natl Acad Sci USA 2005; 102:10652-10657.

20. Negrete OA, Levroney EL, Aguilar HC, et al. EphrinB2 is the entry receptor for Nipah virus, an emergent deadly paramyxovirus. Nature 2005; 436:401-405.

21. Negrete O, Wolf M, Aguilar H, et al. Two Key Residues in EphrinB3 Are Critical for Its Use as an Alternative Receptor for Nipah Virus. PLoS Pathog 2006; 2:1227-1336.

22. Bishop K, Stantchev T, Hickey A, et al. Identification of Hendra virus $G$ glycoprotein residues that are critical for receptor binding. J Virol 2007; 81:5893-5901.

23. Zhu Z, Bossart K, Bishop K, et al. Exceptionally potent crossreactive neutralization of Nipah and Hendra viruses by a human monoclonal antibody. J Infect Dis. 2008; 197:846-853.

24. Yob JM, Field H, Rashdi AM, Morrissy C, van der Heide B, et al. Nipah virus infection in bats (order Chiroptera) in peninsular Malaysia. Emerg Infect Dis. 2001; 7:439-441.

25. Reynes J, Counor D, Ong S, Faure C, Seng V, et al. Nipah virus in Lyle's flying foxes, Cambodia. Emerg Infect Dis. 2005; 11:1042-1047.Hayman DT, Suu-Ire R, Breed AC, Mc

26. Eachern J, Wang L, et al. Evidence of henipavirus infection in West African fruit bats. PLoS One. 2008; 3:2739.

27. Li Y, Wang J, Hickey AC, et al. Antibodies to Nipah or Nipah-like viruses in bats, China. Emerg Infect Dis. 2008 14:1974-1976.

28. Halpin K, Hyatt AD, Fogarty R, et al. Pteropid bats are confirmed as the reservoir hosts of henipaviruses: a comprehensive experimental study of virus transmission. Am J Trop Med Hyg. 2011; 85:946-951.

29. Field H, Mackenzie J, Daszak P. Henipaviruses: emerging paramyxoviruses associated with fruit bats. Current Topics Micro and Immuno 2007; 315:133-159.

30. Gurley E, Montgomery J, Hossain M. Person-to-person transmission of Nipah virus in a Bangladeshi community. Emer Infect Dis. 2007; 13:1031-1037.

31. Hossain M, Gurley E, Montgomery J. Clinical presentation of Nipah virus infection in Bangladesh. Clin Infect Dis 2008; 46:977-984

32. Lee K, Umapathi T, Tan CB. The neurological manifestations of Nipah virus encephalitis, a novel paramyxovirus. Annals of Neuro 1999; 46428-46432.

33. Lim C, Lee K, Lee W. Nipah virus encephalitis: Serial MR study of an emerging disease. Radiology 2002; 222:219-26.

34. Bloch A, Orenstein W, Stetler H, Wassilak S, Amler R Health impact of measles vaccination in the United States. Pediatrics 1985; 76: 524- 532.
35. Orenstein W, Papania M, Wharton M. Measles elimination in the United States. J Infect Dis 2004; 189:S1-3.

36. Promed 20110526.1603 (2011) Rinderpest - worldwide: global eradication.

37. Graham B, Crowe J. Immunization against viral diseases. In: Knipe DM, Griffin DE, Lamb RA, Straus SE, Howley PM et al., editors. Fields Virology. Philadelphia: Lippincott Williams \& Wilkins. 2007; 487-538.

38. Plotkin SA. Vaccination against the major infectious diseases. C R Acad Sci III 1999; 2:943-951.

39. Wolinsky J, Waxham M, Server AC. Protective effects of glycoproteinspecific monoclonal antibodies on the course of experimental mumps virus meningoencephalitis. J Virol 1985; 53:727-734

40. de Swart R, Yuksel S and A. D. M. E. Osterhaus. Relative contributions of measles virus hemagglutinin- and fusion protein-specific serum antibodies to virus neutralization. J. Virol. 2005; 79:11547-11551.

41. Weingartl H, Berhane Y, Caswell J, Loosmore S, Audonnet J. Recombinant nipah virus vaccines protect pigs against challenge. J Virol 2006; 80:7929-7938

42. Guillaume V, Contamin H, Loth P, Georges-Courbot M, Lefeuvre A. Nipah virus: vaccination and passive protection studies in a hamster model. J Virol 2004; 78:834-840.

43. Giraudon P, and Wild T. Correlation between epitopes on hemagglutinin of measles virus and biological activities: passive protection by monoclonal antibodies is related to their hemagglutination inhibiting activity. Virol 1985; 144:46-58.

44. Griffin DE. Knipe D and Howley P. Fields virology, Lippincott Williams \& Wilkins, Philadelphia. 4th ed. 2001; 1401-1441

45. Mohd Nor M, Gan C, Ong B. Nipah virus infection of pigs in peninsular Malaysia. Rev Sci Tech 2000; 19:160-165.

46. Malvoisin E and F. Wild. Contribution of measles virus fusion protein in protective immunity: anti-F monoclonal antibodies neutralize virus infectivity and protect mice against challenge. J Virol 1990; 64:5160-5162.

47. Weingartl H, Czub J, Copps Y, Berhane D, Middleton P, Marszal J, Gren G, Smith S. Invasion of central nervous system in a porcine host by Nipah virus. J. Virol 2005; 79:7528-7534.

48. Mungall B, Middleton D, Crameri G, Bingham J, Halpin K. Feline model of acute Nipah virus infection and protection with a soluble glycoprotein based subunit vaccine. J Virol 2006; 80:12293-12302.

49. McEachern J, Bingham J, Crameri G, Green D, Hancock T. A recombinant subunit vaccine formulation protects against lethal Nipah virus challenge in cats. Vaccine 2008; 26:38423852.

50. Pallister J, Middleton D, Wang L, Klein R, Haining J. A Recombinant Hendra virus G Glycoprotein-Based Subunit Vaccine Protects Ferrets from Lethal Hendra virus Challenge. Vaccine: 2011; 29:5623-5630.

51. Snoy PJ. Establishing efficacy of human products using animals: the US food and drug administration's "animal rule". Vet Pathol 2010; 47:774-778.

52. Rockx B, Bossart K, Feldmann F, Geisbert J, Hickey A. A novel model of lethal Hendra virus infection in African green monkeys and the effectiveness of ribavirin treatment. J Virol 2010; 84:9831-9839

53. Geisbert T, Daddario-DiCaprio K, Hickey A, Smith M, Chan Y. Development of an acute and highly pathogenic nonhuman primate model of Nipah virus infection. PLoS ONE 2010; 5:e10690

54. Williamson M, Torres-Velez F. Henipavirus: a review of laboratory animal pathology. Vet Pathol 2010; 47:871-880. 